\title{
Cervical Cytology Screening in the Army
}

Major M S Zaklama, MB, ChB, MRCOG, RAMC

British Military Hospital, Rinteln BFPO 29

Dr J A Birkett, MB, ChB, DRCOG, DCH

Medical Centre, Minden, West Germany

SUMMARY: A survey of 748 Army women showed an excellent screening rate for cervical cytology without the use of a screening programme. The women's knowledge regarding results of smears was, however, poor, even in cases with proven carcinoma. Frequent movement of the women because of postings makes follow-up cytology difficult, and a proposal is put forward for a positive reporting system. In this survey severe dyskaryosis suggestive of carcinoma of the cervix was seen presenting under the age of 35 years.

\section{Introduction}

Cervical carcinoma is the third commonest malignancy in women. It is relatively easy to detect and has a high chance of cure. Cervical cytology was introduced by Panpanicolaou in 1943, and was the first screening procedure for malignant disease. Population screening programmes for cervical carcinoma using cervical cytology have reduced significantly the incidence of carcinoma of the cervix. Current annual death rates for England and Wales stand at one woman in every 12,500 .

Evidence suggests a significant increase in preinvasive and invasive disease, with the increase occurring dramatically in the 25-34 year age group'. This particular age is well represented in the population served by the Army Medical Services; few women over 40 years of age, and very few over 50 are still under the care of the Army Medical Services.

Follow-up is essential for all women who have had abnormal cytology (dyskaryosis or atypia of any degree). This should continue whether there has been apparent regression in the form of subsequent negative smears, or after any form of treatment.

The media has recently focused attention on cervical carcinoma, with particular emphasis on cervical screening programmes following the tragic events in $\mathrm{Oxford}^{2}$. After such publicity, do the women understand why they should attend for a cervical smear, how often it should be repeated, and what importance to attach to the result?

This survey aimed to establish how effectively the population was screened for cervical carcinoma, and to evaluate the women's knowledge of their cervical smear record.

\section{Method}

A questionnaire was drawn up and distributed randomly in two locations - a Garrison Medical Centre and the Gynaecological and Obstetric Outpatients Department of the teaching Military Hospital serving that medical centre. Care was taken to avoid duplication. The questionnaire was completed whilst the

women sat in the waiting room and handed to the receptionist before they saw the doctor. Information was gathered over a three month period in July/ September 1985.

The questionnaire was a simple one in which the women were asked to identify themselves by surname, husband's Army number or civilian unit, and age.

They were then asked:

1. The date of their last cervical smear

2. If they had knowledge of the result

3. If any further medical care ensued as a result of cervical smear

4. Their current form of family planning

5. To indicate if they had any inquiry about cervica smears.

After assessing the initial results it was decided to extend the survey to compare the answers from the questionnaire with the patients' medical documents. It was possible to attempt this in 405 cases where either the cervical smear result was within the hospital documents or the woman was registered with the Medical Centre initiating the questionnaires. The women's medical records were searched for the date and result of the last cervical smear as well as the doctor's findings at the time of examination.

\section{Results}

748 questionnaires were completed. There were, surprisingly, no spoiled forms.

The age distribution (Fig 1) showed that $621(83 \%)$ women were in the 20 to 34 year range, with $4(1 \%)$ women at 45 and over. Of the 748 women, $50(7 \%)$ had never had a smear. These 50 women were distributed amongst all the age groups but $31(4 \%)$ were under 20 years.

Of the remaining 698 women, all claimed to have of undergone at least one cervical smear, and $594(85 \%)$ were able to recall the date on which it had been done. N Twenty one $(3 \%)$ of these dates were more than 5 years previously. When asked to recall the results of the last cervical smear, $142(20 \%)$ claimed to know the result, and $158(23 \%)$ had relied on negative reporting (i.e., the 


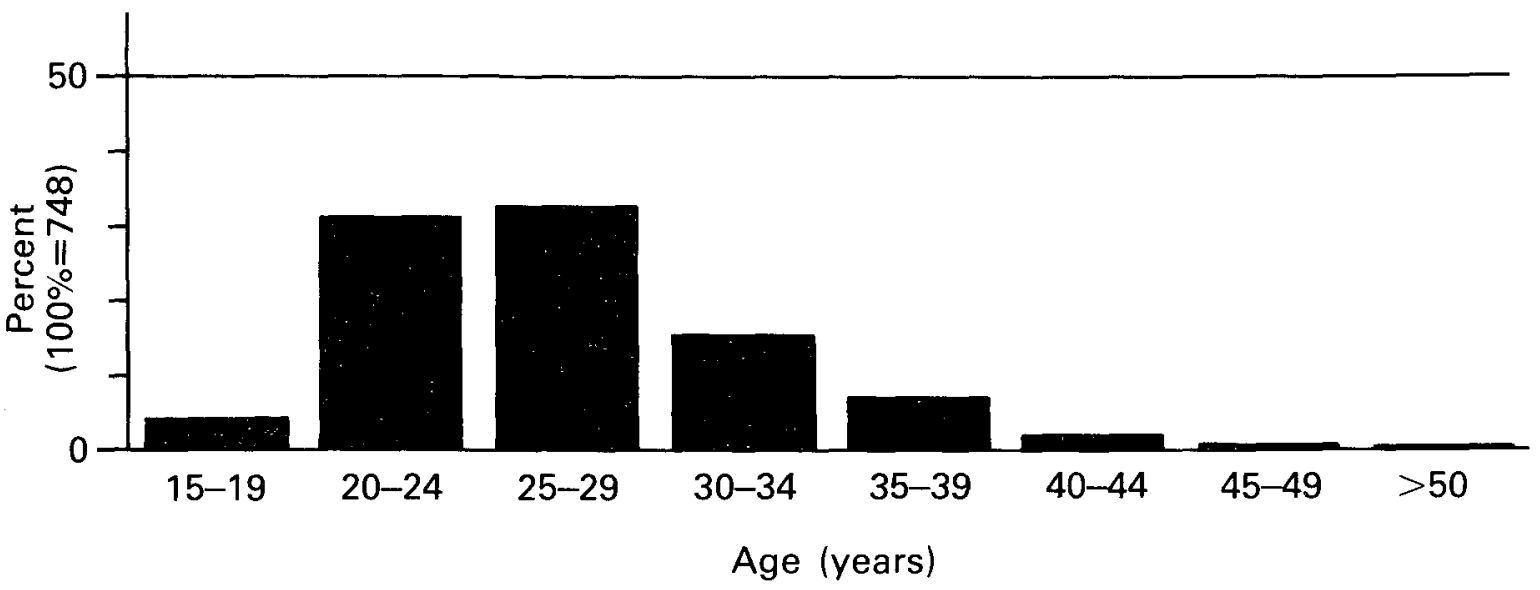

Figure 1: Age distribution of women in study

woman is only informed if the result is abnormal, and no further communication from the doctor after the smear indicates a normal result). The remaining $398(57 \%)$ women who claimed to have undergone a cervical smear had no idea of the result. (Table 1).

Table 1

Total Survey - Questionnaire Results

Responses of the 698 women (93\% of the total) who claimed to have had a cervical smear.

\begin{tabular}{lll}
\hline & $\begin{array}{l}\text { DATE } \\
\text { of smear }\end{array}$ & $\begin{array}{l}\text { RESULT } \\
\text { of smear }\end{array}$ \\
\hline AWARE & $\begin{array}{l}(3 \% \% \\
\text { previously })\end{array}$ & $20 \%$ \\
\hline UNAWARE & $15 \%$ & $\begin{array}{l}57 \% \text { No idea } \\
23 \% \text { Relied on negative } \\
\text { reporting }\end{array}$ \\
\hline
\end{tabular}

Because of abnormal cervical cytology $30(4 \%)$ of the women were referred for further investigation and/or treatment. Five women had undergone hysterectomy and 4 had cone biopsies following smear reports showing severe dyskaryosis amounting to carcinoma-in-situ. Eleven women required follow-up for dyskaryosis of milder degrees, and 10 women were having repeat cervical smears for other reasons such as inflammation, poor smear technique, post-natal changes, etc. The 9 women $(1.2 \%$ total survey population) who had undergone hysterectomy or cone biopsy were all in the $25-34$ age group. Of the 11 women having continuing follow up for dyskaryosis, 9 were in the 25-34 age range with 2 over 34 years.
Methods of family planning are shown in Table 2. Within the group of women not using any form of contraception, 161 were attending ante-natal clinic.

Only $37(5 \%)$ of the women wished to make an enquiry about cervical smears.

The extended survey involved 405 women. (Table 3 )

On checking the records of the 303 women who claimed to know the date of their last smear, $236(78 \%$ o were correct, $30(10 \%)$ were incorrect, and in $36(12 \%$. no medical records were available. Of the 30 women who were incorrect, $18(6 \%)$ had never had a smeas done at any time. This group had been confused either by a vaginal examination and/or a high vaginal swab. Of the 75 women who did not know the date of their last smear, no record could be found in $10(15 \%)$ while all the remaining $64(85 \%)$ had had a smear within the last five years. Of the 27 women who claimed never to have had a smear, on checking their records, 2 had in fact had one within the last 5 years.

From the questionnaire, of the 405 women in the extended survey, 80 had claimed to know the results of their last smear, whilst 74 had relied on negative reporting, with the remaining 251 having no idea of the result.

Table 2

Methods of Family Planning used at the time of the survey

\begin{tabular}{ll}
\hline METHOD USED & \% (of 748) \\
\hline None/Pregnant & 38 \\
Oral contraception & 36 \\
IUCD & 7 \\
Sterilized & 7 \\
Vasectomy & 5 \\
Condom & 4 \\
Hysterectomy & 2 \\
Others & 1 \\
\hline
\end{tabular}


Table 3

Extended Survey - Questionnaire Results of 405 Women compared with Medical Record Search Findings

\begin{tabular}{|c|c|c|c|c|}
\hline & DATE of smear & DATE of smear & RESULT of smear & RESULT of smear \\
\hline AWARE & $80 \%$ & $\begin{array}{l}62 \% \text { Correct } \\
3 \% \text { Incorrect } \\
5 \% \text { Never had smear } \\
10 \% \text { No records }\end{array}$ & $21 \%$ & $\begin{array}{l}18 \% \text { Correct } \\
3 \% \text { No records }\end{array}$ \\
\hline UNA WARE & $20 \%$ & $\begin{array}{l}17 \% \text { Had smear within } \\
\text { last } 5 \text { years } \\
3 \% \text { No record }\end{array}$ & $\begin{array}{l}59 \% \text { No idea } \\
\begin{array}{l}20 \% \text { Relied on negative } \\
\text { reporting }\end{array}\end{array}$ & $\begin{array}{l}34 \% \text { Normal Cytology } \\
5 \% \text { Abnormal Cytology } \\
3 \% \text { Unsatisfactory smear } \\
7 \% \text { No records } \\
16.8 \% \text { Normal Cytology } \\
0.2 \% \text { ( } 1 \text { woman) abnormal Cytology } \\
3 \% \text { No records }\end{array}$ \\
\hline
\end{tabular}

In the cases of $10(12 \%)$ of the 80 women who claimed to know the result of their last smear, no medical records were available. Of the remaining $70(88 \%)$ all knew correctly the result, whether it was negative or positive, but only 4 of these women had been informed in writing of a negative result by the doctor who received the laboratory report.

Within the group of 74 women who had relied on negative reporting, a review of the medical records showed that one woman had actually undergone hysterectomy for carcinoma in-situ of the cervix, and was not returning for follow up. In this group $12(16 \%)$ medical records were available.

Of the 251 women who said that they were unaware of the results of their smear, the medical records showed that $206(82 \%)$ had had a normal cytology report, 10 $(4 \%)$ had cytologically unsatisfactory smears and had failed to return for a repeat testing, and in $26(10 \%)$ the medical records were unavailable. Of the remaining 9 $(4 \%), 1$ woman had undergone hysterectomy for carcinoma in-situ of the cervix, 1 woman had required a cone biopsy for suspected carcinoma in-situ and 7 women were having repeat smears because previous reports had shown dysplasia. In total, 9 women were unaware of significant cervical pathology, and another 10 were unaware they still remained effectively unscreened.

\section{Discussion}

The population of the survey is not representative of the UK as a whole. The majority of women cared for by the Army Medical Services are under the age of 45 years, since after this age the population within the Army either actively serving or as dependants is very much smaller.
It is interesting to find that within this survey with itso large group of 25-35 age range, all the histologicall $\vec{\Phi} \overrightarrow{.}$ confirmed cases of carcinoma of the cervix have bee $c$ under the age of 35 . This earlier age of presentation ha $\bar{\nabla} \vec{\nabla}$ been well documented in studies from Britis Columbia ${ }^{3,4}$.

A cervical cytology screening programme is difficule to organise within the Army Medical Services due to the mobility of the population because of postings. Cervices smears are offered at both Medical Centres and Gynaecology Outpatients where women attend for routine appointments, or at specialist clinics (family planning, ante/post natal, infertility, etc).

Overall, the survey was encouraging in that even without an established screening programme, the majority $(90 \%)$ claimed to have had a cervical smear within the last 5 years. A high proportion $(85 \%)$ were able to give the date when this was taken. However, it was alarming to find the high percentage of women $(57 \%)$ who were unaware of the results of their cervical smears, and to find an additional $23 \%$ relying on negative reporting.

Extension of the survey to check the accuracy of the women's answers on dates and results of their cervical smears showed some discrepencies, but these were not numerically large.

More interestingly the review of the medical records showed that $10(4 \%)$ of women who claimed to be quite unaware of the results of their smears or who had relied on negative reporting, had actually had abnormal cytology reports. Of these 10 cases, 2 had had hysterectomy for pathological changes amounting to carcinoma in-situ of the cervix, one case had had a cone biopsy for suspected carcinoma in-situ, and 7 cases were having repeat smears for successive reports of dysplasia. Also of note are the 18 women who had mistaken a 
vaginal examination or the taking of a vaginal swab for a cervical smear, and the 10 women with cytologically unsatisfactory smears who failed to return for follow up. All 28 women remain unscreened for cervical abnormalities. Conversely 2 of the 27 women who thought they had never had a smear had in fact had one.

Very few women were "out of date" for smears (using the 5 year recall period as recommended by the RCOG). Macgregor ${ }^{5}$, in 1985 , claimed that screening women from 20 years of age at 3 yearly intervals would reduce the incidence of invasive cervical carcinoma by $91 \%$. During the medical record search, it was noted that women were having smears far more frequently than every 5 years. Indeed, a criticism could be made of an excessive rate of cervical smears, in that annual smears with negative results were frequently noted. Those 21 who had had their last smear more than 5 years previously fell into categories who were not childbearing, and were therefore not "caught" in the ante-natal, post-natal or family planning screen. Women who had been sterilised constituted the largest number of this group (15 of 21).

There were 50 women who had never had a smear. This may be acceptable for the 31 women under 20 years, but the remaining 19 women had missed cervical screening despite passing through different channels of medical care for a variety of reasons which included family planning and child bearing.

A very small number of women requested information about either their own smear or smears in general. This seemed surprising in view of the anxiety anticipated following the recent publicity.

In the course of this review, of 405 women, it was noted that medical records were unavailable for 47 $(12 \%)$. This is probably due in large part to the frequent movement of the women, and failure to register properly with a new doctor. Even following correct registration on arrival in a new posting there is a delay, sometimes involving months, before the medical records pass through the normal administrative channels. More problems arise when a woman on leave in $\mathrm{UK}$, mistakenly registers with a doctor as a new patient instead of temporary resident, or attends an independent clinic (well woman or family planning) for a cervical smear without leaving a forwarding address for the results. Some women in this survey were registered for German medical care, and medical records on them were unobtainable.

\section{Conclusion}

This survey shows a very satisfactory screening rate $\stackrel{\mathbb{Q}}{\stackrel{2}{2}}$ for cervical cytology without the use of a specific $?$ screening programme for the population served by the Army Medical Services. Additional attention should perhaps be given to those minority groups who are not $\vec{F}$ "caught" in the established nets for cervical screening.

Large numbers of women have no idea of the results of their last smear and there are instances of failure of follow up in cases of abnormal cytology. It would seem that improved communication with the women is of paramount importance to secure their active participation in the process of cervical screening.

With this aim in view, a system of positive reporting for the women cared for by the Army Medical Services is proposed. Such a system would take the form of a card or booklet, which would be the property of the woman herself, and be completed by the relevant doctor. This card or booklet should contain details of cervical smears, giving dates, results, and the advised date of the next cervical smear. A second section could contain the contraceptive and obstetric record, with a third section $\overrightarrow{0}$ for details of any gynaecological surgery.

The responsibility for the card or booklet would reg with the woman concerned, and she would present it ti her new doctor for information on registering. Af opportunity would thus be provided for an accurate anf immediate assessment of each woman with regard to cervical cytology, and to initiate screening and/or follow up where considered necessary, and to encourage the women themselves to take a positive role in important area of preventive medicine.

\section{REFERENCES}

1. DRAPER $\mathbf{G} \mathbf{J}$ and $\mathrm{COOK} G \mathrm{G}$. Changing patterns of cervica carcinoma rates (leader) $B r$ MedJ 1983; 2: 510-12.

2. House of Commons Debate. Serious deficiencies in cervical screening Lancet 1985; 1: 766.

3. Walton R J. Canadian Task Force Report (1976) Cervical Cancer Screening Programmes, Can Med AssocJ 1976; 114: 1003-1033.

4. Walton R J. Canadian Task Force Report (1982) Cervical Cancer Screening Programmes, summary of the Canadian Task Force Report. Can Med Assoc J 1982; 127: 581-589.

5. Macgregor J. Lecture to Marie Curie Foundation Meeting 1985.

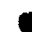

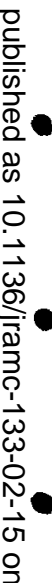

